\title{
Games e moralidade: como os jogadores se relacionam com os conteúdos morais dos jogos?
}

\author{
Games and morality: how do players \\ relate to the moral content of games?
}

\section{Vítor de Morais Alves Evangelista' ${ }^{1}$ Aline Kadooka ${ }^{2}$ (1) Rita Melissa Lepre ${ }^{3}$ (1)}

\author{
'Universidade Estadual do Norte do Paraná (Cornélio Procópio). Paraná, Brasil. vitordemorais@hotmail.com \\ ${ }_{2}^{2}$ Secretaria Municipal de Educação e Cultura (Sertaneja). Paraná, Brasil. alinekadooka@gmail.com \\ 3Universidade Estadual Paulista (São Paulo). São Paulo, Brasil. melissa.lepre@unesp.br
}

RESUMO | INTRODUÇÃO: Os jogos eletrônicos se tornaram parte fundamental de uma sociedade marcada pelo uso da tecnologia e pela virtualização das relações humanas. Considerados como produto de uma cultura de consumo tecnológica recente, os jogos apresentam a seu respeito diversas opiniões contraditórias, principalmente às que se referem aos seus conteúdos morais e suas supostas influências. OBJETIVO: A presente pesquisa tem como objetivo analisar como os jogadores se relacionam com os conteúdos morais presentes nos jogos eletrônicos. METODOLOGIA: Trata-se de um estudo quanti-qualitativo envolvendo 30 jogadores. Recorreu-se a entrevistas semiestruturadas com a apresentação de dilemas virtuais baseados em jogos eletrônicos. As entrevistas foram transcritas e analisadas por meio de análise de conteúdo e estatística descritiva, sendo os resultados discutidos à luz das teorias morais. RESULTADOS E DISCUSSÃO: Os resultados apontam que a maioria dos jogadores considera o ambiente virtual como um espaço de permissividade, satisfação dos desejos e livre de qualquer sanção, apresentando um número bem maior de respostas utilitaristas aos videodilemas. CONCLUSÃo: Os resultados sugerem que a ação moral no ambiente virtual pode ser vista como um construto independente para o julgamento moral.

\begin{abstract}
INTRODUCTION: Electronic games have become a fundamental part of a society marked by the use of technology and the virtualization of human relationships. Games, considered a product of recent technological consumer culture, have several contradictory opinions about them, mainly those referring to their moral content and their supposed influences. OBJECTIVE: This research aims to analyze how players relate to the moral content present in electronic games. METHODOLOGY: This is a quantitative and qualitative study involving 30 players. Semi-structured interviews were used with the presentation of virtual dilemmas based on electronic games. The interviews were transcribed and analyzed through content analysis and descriptive statistics, and the results were discussed in the light of moral theories. RESULTS AND DISCUSSION: The results show that most players consider the virtual environment space of permissiveness, satisfaction of desires, and freedom from any sanctions, presenting a much larger number of utilitarian responses to video dilemmas. CONCLUSION: The results suggest that moral action in the virtual environment can be seen as an independent construct for moral judgment.
\end{abstract}

KEYWORDS: Games. Moral. Virtual.

PALAVRAS-CHAVE: Jogos. Moral. Virtual. 


\section{Introdução}

A sociedade contemporânea está cada vez mais direcionada ao virtual. O virtual nunca esteve tão bem representado e tão presente nas relações humanas. A superação das barreiras geográficas e temporais propiciou o virtual como nova forma de socialização e parte integrante da atual constituição de uma sociedade individualista (Giddens, 1991). O virtual surge, então, como uma forma de prover a felicidade e satisfação dos desejos em um universo de possibilidades. Os jogos eletrônicos são elementos fundamentais nesse processo de virtualização. McGonigal (2012) aponta que o "êxodo em massa" para os espaços virtuais indica uma situação de esgotamento do real, tendo em vista que a realidade não oferece tanta facilidade em se obter e prazeres e emoções em comparação aos ambientes virtuais. Para a autora, os jogadores de videogame estão cansados da realidade. Todavia, isso não quer dizer que é um abandono completo, pois os jogadores possuem empregos, deveres, objetivos, famílias e compromissos com a vida real, mas passam a dedicar uma parcela maior do tempo livre em mundos virtuais mais atraentes que o mundo real.

A evasão é o sustentáculo do consumo cultural. Ela é o novo ópio de uma sociedade disposta a olvidar as condições monótonas e as frustrações do cotidiano - a ansiedade e a solidão -, assim "consumimos em espetáculo aquilo que a vida real nos recusa: sexo porque estamos frustrados, aventura porque nada de palpitante agita nossas existências no dia a dia" (Lipovetsky, 2009, p. 258).

Para Salen e Zimmerman (2012) embora os jogos possam produzir redes complexas de desejo, alívio, ansiedade, conhecimento e prazer, além de inspirar e abordar os temas profundos da existência humana de modo diferente de qualquer outro meio de comunicação, muitos jogos ainda se encontram atrofiados, condenados a alguns prazeres familiares como, por exemplo, sexo, violência, agressividade e violação de regras. Esse atrofiamento foi causado pela submissão das potencialidades dos jogos frente aos ditames do mercado da grande indústria de jogos. A capacidade de processamento tecnológico dos consoles atuais possibilitam a criação de jogos com diferentes narrativas, dinamismos e gráficos cinematográficos que produzem sensações de imersão e liberdade. Tal capacidade, contudo, gera críticas e perseguições moralistas.
Khaled Jr (2018) aponta que o pânico moral em torno dos jogos eletrônicos surgiu na segunda metade dos anos 1970 e disseminou-se nas décadas posteriores. Uma das consequências desse pânico seria o senso comum de que os jogos e a violência estão sempre relacionados. Tal conexão, difusora de pânico moral, acaba por resultar na criminalização cultural dos jogos eletrônicos, dos criadores e também dos jogadores. Para Lipovetsky (2016), assim como ocorre a depreciação da razão e dos deveres, os imperativos incondicionais destinados a honrar os deveres da moral também perderam toda veracidade no atual contexto pós-moderno. O cumprimento do dever "agora ou nunca" deu lugar a busca de prazeres, de formas de bem-estar e de informações. Na relação entre jogador e jogo, o virtual é criado como um espaço peculiar, uma dimensão na qual o jogador imerge em um mundo com diferentes possibilidades, personalidades e poderes, um alívio em meio às regras e sanções da realidade.

Haidt (2018) defende uma concepção da moralidade na qual os sistemas morais são conjuntos de virtudes, regras, práticas, instituições e mecanismos psicológicos com o propósito principal de restringir o autointeresse e possibilitar a cooperação social. Tais sistemas morais têm como base as intuições morais que brotam de modo instantâneo e automático, antes de se iniciar qualquer processo de raciocínio moral. Tal visão explicaria o motivo de pessoas provenientes das mais variadas culturas e com os mais variados graus de instrução, possuírem opiniões distorcidas e tendenciosas ao participarem de debates morais. Para o autor, ao condenar certas atitudes, as pessoas o fazem por achar ofensivo e não porque utilizam sua razão. Se questionadas pelos motivos de tais decisões morais, as pessoas não conseguem argumentar suas decisões. A racionalização, dessa forma teria como função justificar nossas reações emocionais;

Para Greene (2018), a moral é um elemento fundamental na evolução de nossa espécie, que fez com que desenvolvêssemos a capacidade de cooperação sendo que os sentimentos conduzem nossos julgamentos deontológicos, enquanto os julgamentos utilitaristas nos levam a ações mais frias e calculistas.

A moralidade e a possibilidade de ação têm sido associadas a estruturas adaptativas que examinam as percepções da moralidade e regulam os comportamentos sociais (Ellemers et al., 2013; Francis et al., 2017). 
O elemento preditivo da moralidade pode desempenhar papel subsequente na percepção social, auxiliando na identificação, entre os membros do grupo, de indivíduos potencialmente benéficos ou prejudiciais (Fiske, 2018). Dessa forma, indivíduos que expressam valores não utilitários são percebidos como mais confiáveis e subsequentemente preferidos como parceiros em um contexto social, demonstrando essa função adaptativa. lachini et al. (2015) indicou que tal qualidade preditiva não está relacionada somente ao ambiente físico, já que as descrições morais e imorais dos avatares virtuais afetam as ações subsequentes no ambiente virtual.

A presente pesquisa tem como objetivo analisar como os jogadores se relacionam moralmente com os conteúdos morais presentes nos jogos eletrônicos se justificando pela necessidade de estudos relacionados aos jogos eletrônicos e ao dimensionamento de questões relativas à moralidade na contemporaneidade. Entendemos que os jogos, embora voltados à recreação, são considerados como produto de uma cultura de consumo tecnológica recente e apresentam a seu respeito diversas opiniões contraditórias, principalmente às que se referem aos conteúdos morais.

\section{Método}

Trata-se de um estudo quanti-qualitativo desenvolvido por meio de entrevistas semiestruturadas e uso de videodilemas, dilemas virtuais baseados em jogos eletrônicos. Como forma de análise, foi utilizada a análise de conteúdo por meio do software NVivo 11 (QSR International). Os resultados foram discutidos à luz das teorias morais, com ênfase da psicologia moral e teorias pós-modernas.

\section{Participantes}

O critério de amostragem seguiu a abordagem qualitativa, na qual, a amostragem eficiente é aquela que permite abranger a totalidade do problema a ser investigado, em todas as suas dimensões. A amostragem por conveniência esta relacionada à dimensão do objeto, que por sua vez, articula com o grupo pesquisado. Participaram da presente pesquisa 30 jogadores com idade entre 12 e 30 anos de ambos os sexos. Os sujeitos foram recrutados, via convite, em comunidades onlines sobre jogos e em universidades.

\section{Instrumentos}

O roteiro de entrevista semiestruturada consistiu de dezesseis itens mesclando questões abertas e fechadas. As questões abrangeram dados sociodemográficos, formas de acesso aos jogos, escolha de avatares, predileções, motivações e comportamentos durante os jogos. Como forma de análise das opiniões dos jogadores sobre os conteúdos morais existentes nos jogos eletrônicos, foi utilizada a técnica de discussão de dilemas morais.

Elaborada na primeira metade da década de 1970 por Moshe Blatt e Kohlberg, a técnica de discussão de dilemas morais visava a promoção do desenvolvimento moral. O método de discussão de dilemas morais se tornou popular entre as pesquisas envolvendo a moralidade, primeiro por não usar de relativismo nem doutrinação, e segundo, por envolver a crítica às maneiras de formulação de julgamentos morais sem estabelecer respostas corretas (Biaggio, 2006). Biaggio também ressalta a importância de se adequar os dilemas ao contexto em que os indivíduos estão inseridos, pois a moralidade é essencialmente social e, dessa forma, foram elaborados videodilemas, dilemas no formato vídeo construídos a partir das histórias, imagens e sons dos próprios jogos. Três jogos foram escolhidos: Red Dead Redemption (jogo eletrônico de ação-aventura desenvolvido e publicado pela Rockstar em 2010), The Walking Dead (um jogo de ação, estilo survival e interativo, desenvolvido e publicado pela Telltale Games em 2012) e The Last of Us (jogo eletrônico de ação-aventura desenvolvido pela Naughty Dog e publicado pela Sony Computer Entertainment em 2013). A Tabela 1 apresenta os dilemas morais utilizados na pesquisa com os jogadores.

\section{Aspectos Éticos}

A presente pesquisa foi aprovada pelo Comitê de Ética, parecer 48627715.6.0000.540, tendo sido obtidos termos de assentimento e consentimento dos participantes e, quando necessário, dos respectivos responsáveis.

\section{Coleta de Dados}

A coleta de dados foi realizada de forma presencial em encontros de aproximadamente 60 minutos. 
O primeiro procedimento realizado foi a entrevista semiestruturada, seguida da apresentação dos videodilemas utilizando recursos multimídia (notebook e monitor) seguidos dos inquéritos dos mesmos.

\section{Análise de dados}

A análise foi realizada em duas etapas: a primeira foi a análise de conteúdo das questões abertas da entrevista semiestruturada, na qual foram realizadas as seguintes fases: 1) Pré-análise com a leitura do material produzido pela entrevista, escolha dos documentos a serem analisados e retomada dos objetivos e hipóteses da pesquisa; 2) Exploração do material com nova releitura, identificação de núcleos temáticos e categorização das respostas; 3 ) Tratamento dos resultados obtidos e interpretação. As análises foram realizadas com o auxílio do NVivo 11 (QSR International) - um software que suporta métodos qualitativos e variados de pesquisa, projetado para organizar, analisar e encontrar informações em dados não estruturados ou qualitativos. A segunda etapa de análise ocorreu em torno dos dados quantitativos da entrevista, analisados por meio de medidas descritivas (cálculos de frequências, cruzamento de variáveis, cálculos de porcentagem, média e desvio-padrão) com o uso do programa Statistica 6.1 (StatSoft, Inc.) e do editor de planilhas Microsoft Office Excel.

Tabela 1. Dilemas Morais

\begin{tabular}{|c|c|}
\hline Dilema & Resumo \\
\hline $\begin{array}{l}\text { Dilema I - Red Dead } \\
\text { Redemption }\end{array}$ & $\begin{array}{l}\text { John Marston é um criminoso aposentado, anteriormente integrante de uma } \\
\text { gangue. Eles roubavam bancos, trens e matavam inocentes. Um dia, John Marston } \\
\text { acabou conhecendo Abigail, uma prostituta e resolve abandonar sua vida de } \\
\text { bandido. John passa a ser tratado como traidor pelos companheiros, sendo } \\
\text { abandonado pela gangue após ser baleado. John se recupera, monta uma pequena } \\
\text { propriedade, onde reside com Abigail e seu filho Jack. Quando John finalmente } \\
\text { começou a estabilizar sua nova vida, agentes do governo federal sequestram sua } \\
\text { esposa e seu filho. Os agentes dizem que John deve caçar os principais membros } \\
\text { remanescentes de sua antiga gangue e só assim ele terá sua família de volta. O } \\
\text { que john Marston deve fazer? }\end{array}$ \\
\hline $\begin{array}{l}\text { Dilema II - The Walking } \\
\text { Dead }\end{array}$ & $\begin{array}{l}\text { Após um Apocalipse Zumbi, os sobreviventes buscam refúgio longe das hordas de } \\
\text { zumbis. Lee Everett, um assassino condenado, consegue se libertar durante o } \\
\text { evento, resgata e toma conta de uma garotinha chamada Clementine. Eles acabam } \\
\text { se juntando a um grupo de sobreviventes. Certo dia, um dos membros do grupo, } \\
\text { Glenn, chama por Lee no walkie-talkie e diz que está encurralado no motel. Carley } \\
\text { e Lee vão a sua procura e o encontram escondido na máquina de gelo. Antes de } \\
\text { sair, eles decidem salvar uma garota no andar superior, que Glenn tentara salvar } \\
\text { antes de ficar encurralado. Depois de salvarem-na, descobre-se que a mulher foi } \\
\text { mordida. Já sem muitas esperanças de sobrevivência, a garota pede a arma de } \\
\text { Carley emprestada. O que eles devem fazer? }\end{array}$ \\
\hline Dilema III - The Last of Us & $\begin{array}{l}\text { Grande parte da humanidade foi infectada por esporos do fungo Cordyceps e } \\
\text { transformada em uma espécie de zumbis agressivos. Os sobreviventes tem se } \\
\text { refugiado em cidades afastadas para evitar a contaminação. Joel é um homem, que } \\
\text { assim como todos, perdeu tudo, inclusive a filha, e vive agora com a sua namorada } \\
\text { Tess. Em busca de reaver suas armas, são contratados para levar ao outro lado do } \\
\text { país uma garota de } 14 \text { anos chamada Ellie, que pode ser imune ao Cordyceps e a } \\
\text { única esperança de que uma cura seja finalmente encontrada. Após um ano } \\
\text { enfrentado diversas adversidades e sem Tess, que acabou infectada, Joel e Ellie } \\
\text { chegam ao destino, mas é revelado que para a vacina ser produzida, os médicos } \\
\text { teriam que retirar a amostra do fungo que se alastrou no cérebro de Ellie, ou seja, } \\
\text { ela seria sacrificada. O que Joel deve fazer? }\end{array}$ \\
\hline
\end{tabular}

\section{Resultados e discussão}

\section{Perfil dos jogadores}

A idade média dos jogadores respondentes corresponde a 22 anos. Sobre o grau de instrução, $47 \%$ dos jogadores possuem graduação incompleta, 23,3\% possuem graduação, 13\% possuem ensino médio incompleto, 10\% apresentam pós-graduação e 7\% tem ensino fundamental anos finais incompleto. Quanto ao sexo dos participantes, foram entrevistados 15 participantes do sexo masculino e 15 do sexo feminino. Sobre acesso aos jogos, 56,7\% jogam em computador, $36,6 \%$ possuem consoles, enquanto 6,7\% não possuem videogames ou computadores. 
Todos os jogadores jogam em smartphones. Metade dos jogadores entrevistados joga até 8 horas por dia (50,0\%), $43,3 \%$ jogam até 3 horas e 6,7\% costumam jogar de 8 a 12 horas por dia. Os dados indicam uma quantidade alta de horas de jogo, embora não exista um consenso sobre um número recomendável de horas de jogo.

Przybylski e Mishkin (2015) relataram que não há associação entre jogar games violentos e praticar reais agressões e violência física. A pesquisa analisou os efeitos de diferentes jogos e o tempo gasto sobre o comportamento social e acadêmico em 200 crianças entre 10 e 11 anos. O tempo gasto influencia mais no comportamento social do que o tipo de jogo praticado, e as crianças que costumam jogar mais que 3 horas diárias tem mais probabilidade de desenvolverem hiperatividade, perder rendimento acadêmico ou se envolverem em brigas. Já jogar em pequenas doses, até 1 hora por dia, pode ser benéfico para o comportamento social das crianças. A pesquisa aponta que as consequências negativas de se jogar videogames são pequenas se comparadas a outros fatores que podem influenciar o comportamento de uma criança. Observam-se conforme os dados apresentados e a massiva utilização de smartphones para jogos, uma tendência relacionada ao jogar reativamente sozinho, pois, ao mesmo tempo, pode estar conectado a outras as pessoas. A possibilidade e a preferência por jogar online, graças ao advento da Internet, permitiu a substituição das interações lúdicas cara a cara (Turkle, 2017) e a transformação das redes on-line em comunidades especializadas, produzidas conforme os interesses e predileções específicas de seus usuários (Castells, 2013).

\section{Escolha de avatares}

Na entrevista, duas questões relativas ao uso de avatares, adaptadas de um estudo de Medeiros (2013) sobre jogos virtuais e identidade, foram realizadas: "Como você escolhe seu avatar"? e "Fale um pouco sobre como seria esse avatar". Sobre a primeira questão 43,3\% dos entrevistados escolhem "aquele que se parece comigo", $26,7 \%$ relatam que seu avatar "representa o que eu gostaria de ser" e 13,3\% decidiram que o avatar deve ser "completamente diferente de mim". Já 13,3\% dos jogadores disseram que o avatar "é apenas um boneco" e somente 3,3\% disseram que o avatar "possui vida própria".

Foram analisadas as resposta dos jogadores sobre seus avatares e detectadas quatro categorias referentes à preferência dos jogadores ao criar seus avatares: características físicas (cabelos, olhos, pele, sexo), personalidade (calmo, tranquilo, sorridente, agressivo), habilidades e poderes (guerreiro, atirador, poderes mágicos) e acessórios (tipos de roupas). Os dados apontam que $56 \%$ dos entrevistados elaboram seus avatares ressaltando as Características Físicas, enquanto $18 \%$ preferem a Personalidade. Já 15\% destacam as Habilidades e Poderes, e apenas 11\% apontam os Acessórios como importantes. Ao serem indagados sobre as características de seus avatares, os entrevistados apresentaram diferenças. Os do sexo masculino possuem a tendência de elaborar seu avatar de acordo com as exigências do jogo, tendo como base o estereótipo do soldado atirador ou guerreiro, ressaltando as funções e benefícios inerentes a tais personalidades. Poderes e habilidades dos personagens também são relatados como cruciais à escolha. Já os entrevistados do sexo feminino constroem seu avatar com base em características físicas como cabelos, olhos e itens como roupas e acessórios. Dentre as qualidades mais citadas estão a inteligência, calma, solicitude e amparo.

Mendes (2006) relata que a maioria dos personagens heroicos dos jogos possuem características masculinas, sendo que parte das femininas são moldadas segundo os estigmas sociais e culturais atribuídos à mulher. Quando não estão em posição de dependência, possuem corpos literalmente projetados para seduzir. Segundo Kerr (2003) as jogadoras não se sentiam tão atraídas pelos jogos porque estes eram desenvolvidos, em sua maioria, com base em fantasias machistas. Contudo, com o crescimento de personagens femininas em jogos de ação e aventura as mulheres passaram a ser mais atraídas, pois existe a possibilidade de identificação com tais personagens.

$\mathrm{Na}$ realidade virtual, molda-se e cria-se a si mesmo. A internet contribuiu para a multiplicidade da identidade. Com seu surgimento, as pessoas tem a possibilidade de construir uma personalidade e ainda assim, transitar entre muitas personalidades diferentes. A multiplicidade, flexibilidade, heterogeneidade e fragmentação são características dominantes quanto à identidade humana (Turkle, 2017). As possibilidades de construções e reconstruções do eu são características pós-modernas. Przybylski et al. (2017) testaram a hipótese de que o engajamento em jogos de videogames pode permitir que os jogadores experimentem seus ideais de self. 
Os resultados indicaram que os jogadores se tornam mais motivados e emocionados quando os jogos transmitem experiências vivenciadas pelos próprios jogadores. Outro fator importante é que quanto mais o jogo era congruente com as concepções dos jogadores sobre o ideal de self, mais altos eram os graus de imersão nos jogos.

\section{Práticas e percepções dos jogadores}

De maneira geral os entrevistados relataram a preferência pelas seguintes categorias de jogos: Ação (10,6\%), Jogos de celular (9,1\%), Aventura (7\%), Raciocínio e Estratégia (7\%), Jogos de Tiro ou First Person Shooter (4,1\%), Simuladores e Massive Multiplayer Online (4\%), Esportes (3,6\%), RPG (3,2\%) e jogos de Luta (0,8\%). Dentre os títulos mais citados estão: The Sims, GTA, Candy Crush, Candy Crush Soda, Pro Evolution Soccer (PES), Battlefield, Last of Us e FIFA. Os jogadores apontam vários motivos que os influenciam na hora de eleger os seus jogos preferidos. Dente os elementos mais citados estão: Jogabilidade (46,6\%), Proximidade à Realidade (42,3\%), Evasão (34,9\%), Realização (26,2\%), Entretenimento (17,0\%), Predileção (13,0\%), Raciocínio (11,5\%), Gráficos (5,8\%), Acesso (4,9\%), Fantasia (2,7\%) e Competição (1,2\%).

Dentre as características do jogo que mais agradam aos jogadores está a propriedade de vencer. Os mesmos relataram sentirem-se muito satisfeitos por passarem de fase ou vencerem um inimigo. Para eles, o jogo proporciona o sentimento de empoderamento, tendo a capacidade de superar qualquer desafio ou resolver qualquer problema dentro do ambiente virtual. Aspectos técnicos como gráficos e jogabilidade também foram relatados como grandes influenciadores na escolha dos jogos. Os entrevistados foram inquiridos quanto a existência de alguma ação que eles não fariam em jogo. Duas grandes classes de respostas surgiram. Na primeira, estariam aqueles que disseram que não existia nada que não fariam em um jogo (40,6\%), afinal, era apenas um jogo, e ali podiam tudo, como nos exemplos: "Qualquer ação que o jogo permitir"; "Nenhuma, porque é só um jogo que em nada afeta no meu modo de pensar e agir na minha vida real"; "Como é um jogo tudo vale". Na segunda, estão aqueles que possuíam alguma ressalva em relação às ações que poderiam ser praticadas em um jogo: matar "inocentes" (15,5\%), usar códigos e trapaças $(9,4 \%)$, ofender, cometer suicídio, violência física e sexual (6,3\% cada), ter relações homossexuais, roubar e torturar (3,1\%). As respostas dessa categoria condenaram ações ligadas ao roubo, trapaças e violência, tais como, torturar, estuprar e matar a outros, ou a si mesmo (Tabela 2). No entanto, parte desses respondentes, ao serem novamente inqueridos sobre se fariam tais situações para poderem passar de fase, acabaram cedendo e mudaram as suas opiniões.

Tabela 2. Escolhas dos Jogadores

\begin{tabular}{lc}
\hline Pergunta & $\%$ \\
\hline Prioridades na escolha dos Avatares & 56,0 \\
Caraterísticas físicas & 18,0 \\
Personalidade & 15,0 \\
Habilidades e poderes & 11,0 \\
Acessórios & 100,0 \\
Total & \\
\hline O que os jogadores não fariam em um jogo & 40,60 \\
Nada & 15,5 \\
Matar inocentes & 9,4 \\
Usar Códigos & 6,3 \\
Ofender & 6,3 \\
Suicídio & 6,3 \\
Violência & 6,3 \\
Violência sexual & 3,1 \\
Relações homossexuais & 3,1 \\
Roubar & 3,1 \\
Torturar & 100,0 \\
Total & \\
\hline
\end{tabular}


Se as pessoas pudessem transpor alguma coisa dos jogos para a vida a real, a capacidade de mudar a realidade seria a vencedora com $43 \%$. A segunda seria ter superpoderes ou poderes mágicos (32\%). Além de almejar ter superpoderes, elas gostariam de ficar milionárias com apenas o uso de um código (18\%). Também relataram do desejo de serem imortais (13\%). Cometer atos de violência foi apontado como um desejo a ser realizado na vida real (9\%), assim como usar armas (5\%). Obter sucesso e usar os mais variados códigos de trapaças ficou com $2 \%$.

De maneira geral, os sujeitos demonstram o quanto gostariam que a transposição de obstáculos ou situações difíceis da vida fossem mais fáceis de serem superadas. ao serem questionados sobre "como seria seu jogo ideal", e que elementos seriam essenciais na criação de tal jogo, a resposta foi a de que os jogos devem se aproximar da realidade, "quanto mais próximo ao real, melhor". Outros aspectos interessantes apontados foram a necessidade de personagens com superpoderes e a exigência de mundo aberto com elementos possibilitadores de escolhas, com aventura, desafios, lógica, liberdade e até violência. Para os jogadores entrevistados o jogo opera como um simulacro em que as limitações, regras, punições, vergonha, poderiam deixar de existir. Compreendem-se assim, que a função dos jogos eletrônicos alcançou outro patamar desde sua criação, pois transpassa as suas meras características de entretenimento e diversão e passa a ser visto pelos sujeitos como uma maneira de escapar da vida real, ser quem ou o que quiser, podendo criar a vida almejada e dar vazão aos desejos e deveres dos jogadores. Os sujeitos demonstraram a vontade de mudar ou fugir de alguma parte ou aspecto de sua realidade.

As respostas levam a crer que os jogos funcionam, para nossos entrevistados, como um simulacro de outra vida para alguns. Em vários momentos, emergiu a vontade de ter a liberdade que só é possível nos jogos. Para que essa vontade esteja completa, há uma busca por jogos que se aproximem graficamente da realidade. As respostas demonstram o alto nível de envolvimento do jogador com os jogos, à experimentação de imersão das pessoas em seus personagens e a imensidão de sentimentos que os jogos são capazes de trazer à tona. Embora tenham relatado ser errado matar e cometer atos de violências, consideram que no mundo virtual tudo é permitido. $\mathrm{O}$ virtual ganhou o status de ser um lócus de realização dos desejos, já que seria o lugar em que as pessoas poderiam ser quem quisessem e fazer o que quiserem, pois estariam livres de proibições, sanções, julgamentos ou pudores.

\section{Os Videodilemas}

Os resultados analisados a seguir são provenientes da aplicação dos videodilemas apresentados aos entrevistados no formato vídeo. Conforme a Tabela 3, no dilema 1, Red Dead Redemption, 76,7\% dos participantes optaram por salvar a família em detrimento dos amigos, ex-aliados ou ex-companheiros. De maneira geral, as pessoas demonstraram ser uma escoIha fácil e sem motivos para dúvida, já que alegaram que a família deve vir em primeiro lugar, independentemente da situação.

Poucos mostraram pesar em entregar os membros de sua "ex-gangue", pois os mesmos o abandonaram na hora que mais precisou. Em $23,3 \%$ dos casos os entrevistados também acharam primordial manter a segurança da família; no entanto, questionaram a atitude corrupta do governo ou da polícia, condenando-os e os elegendo como os verdadeiros vilões da história. Expressaram também a dificuldade de entregar e condenar alguém com quem possuíam um vínculo afetivo, já que os membros da gangue o criaram e acolheram depois que os seus pais morreram. Nesse caso, a solução escolhida foi denunciar ou matar os agentes corruptos. Bloom (2014) coloca a família como importantíssima nos estudos sobre os juízos e sentimentos morais. Indignação e cuidado é bem maior para os consanguíneos e a amabilidade por eles é a forma original da moralidade, provendo diretamente da seleção natural. Ser gentil com eles é ser gentil consigo mesmo, já que eles compartilham dos mesmos genes.

Ao contrário de outras espécies, os seres humanos moralizam esses vínculos. Como exemplo, tem-se a valorização dos laços entre pais e filhos e o sentimento de que outras pessoas também deveriam valorizar esses fortes laços, desaprovando os pais ou filhos indiferentes a tal sentimento. $O$ mesmo acontece com os integrantes do grupo, ou seja, indivíduos que pertencem à mesma comunidade ou tribo. Assim como na relação com os parentes, os sentimentos pelo grupo evoluíram como formas de adaptação à vida em sociedade, por meio do benefício mútuo e cooperação dos indivíduos entre si. Haidt (2018) afirma que a lealdade e amor aos companheiros pode se transformar em ódio àqueles que traem o grupo, que 
normalmente são considerados muito piores do que inimigos. Essa reação de possível "ódio" aos companheiros foi apontada como o grande gatilho para que John salvasse sua família em detrimento de seus antigos parceiros.

No dilema 2, The Walking Dead, 70,0\% das pessoas disseram que dariam a arma para a mulher infectada se matar, pois era seu direito. Dentre as respostas arguiram convictamente que ela não teria outra saída, a não ser virar um monstro, portanto, deveriam deixá-la se matar com dignidade e conforme a sua vontade para dar fim ao seu sofrimento. Além disso, relataram que no momento em que pediu a arma para se matar, ela estava com as suas faculdades mentais intactas, ou seja, apta para decidir o que fazer com a sua própria vida. Muitos disseram que a opção de dar a arma para ela se matar era melhor, pois não gostariam de se sentir responsabilizados por uma morte ou se tornarem assassinos. Por outro lado, $26,7 \%$ dos sujeitos disseram que não dariam a arma para ela se matar, mas assumiriam a responsabilidade de matá-la (Tabela 3). Como justificativa, afirmaram que ela já estava condenada a virar zumbi e representaria um perigo ao grupo. Apenas 3,3\% dos entrevistados ofereceram uma outra saída: o argumento principal era de que se tratava de um ser-humano e, portanto, deveriam procurar ajuda e oferecer um tratamento para os sintomas, até que a cura fosse encontrada. Assim como no estudo de Greene (2018) sobre os dilemas dos bondes, nos quais existe a possibilidade de matar um homem como um meio para um fim, a possibilidade de realizar tal ato, ocasiona uma forte reação emocional, muito mais forte do que puxar uma alavanca, ou no caso do dilema 2, entregar a arma para a pessoa. É uma forma de isentar-se de tal responsabilidade, mesmo sabendo que a arma será usada para a mesma finalidade. Segundo Bloom (2014) pode-se ter empatia sem compaixão, ou compaixão sem empatia. Pode-se muito bem sentir o sofrimento da pessoa e desejar parar de sentir isso, mas também escolher resolver a situação distanciando-se da pessoa, em vez de aliviar o seu sofrimento. Neste dilema três categorias de respostas são identificadas e comparadas entre os respondentes do sexo feminino e masculino. Com relação a categoria "Dar a arma", $27 \%$ dos homens não dariam a arma enquanto 33\% das mulheres entregariam a arma para a personagem. Já sobre a categoria "Matá-la", 23\% dos homens tomariam essa decisão, mas apenas $7 \%$ das mulheres cometeriam tal ato. Enquanto $10 \%$ das mulheres tentariam elaborar outras soluções para o dilema, nenhum dos homens respondentes apontou algum tipo de alternativa.

No dilema 3, The Last of Us, 43,4\% dos participantes disseram que sacrificariam Ellie. Como justificativa alegaram que a vontade da menina deveria ser respeitada, já que a sobrevivência da humanidade dependeria disso. Mesmo que Ellie não soubesse que a sua morte seria inevitável para a criação da vacina, ela deveria aceitar as consequências. Portanto, a sua morte seria para atingir um bem maior e consequentemente não seria em vão. Contrários a esses 33,3\% de opiniões se mostrou a favor de salvar a vida de Ellie.

Tabela 3. Resultados dos dilemas

\begin{tabular}{lc}
\hline Dilemas & $\%$ \\
\hline Dilema I - Red Dead Redemption & 76,7 \\
Salvar a família & 23,3 \\
Outros & 100,0 \\
Total & \\
\hline Dilema II - The Walking Dead & 70,0 \\
Matá-la & 26,7 \\
Dar a arma para ela se matar & 3,3 \\
Outros & 100,0 \\
Total & \\
\hline Dilema III - The Last of Us & 43,4 \\
Sacrifica Ellie & 33,3 \\
Não sacrifica & 20,0 \\
Outros & 3,3 \\
Não respondeu & 100,0 \\
Total & \\
\hline
\end{tabular}


Nessas respostas percebe-se um apelo mais sentimental em algumas das justificativas. Em primeiro lugar, a maioria manifestou que a menina deveria ser consultada antes de tomarem uma decisão tão importante como essa, pois só caberia a ela decidir o que fazer. Na impossibilidade de consulta, revelaram que Joel deveria tomar o partido e tirar a menina de lá, já que não existiam garantias de que a vacina seria efetiva. Além disso, outra solução deveria ser encontrada. Entre sacrificar e não sacrificar $20 \%$ das respostas não se posicionaram de maneira unilateral, justificando não serem capazes de tomar essa decisão sem garantias de cura da humanidade ou sem o consentimento da mesma, já que se tratava de uma decisão única e intrasferível, portanto, que só caberia a Ellie. A maioria $(43,3 \%)$ optou pela resposta utilitarista, sacrificar Ellie em prol da humanidade como a promoção de um bem maior. Para aqueles que partilham de uma visão deontológica (33,3\%), é preciso respeitar os direitos das pessoas e não as ferir ou assassina-las como forma de alcançar outros objetivos, mesmo que estes envolvam salvar mais vidas. Seguindo essa proposta, a decisão caberia somente à Ellie.

Para os deontologistas os princípios morais superiores são derivados e justificados pela racionalidade e não por sentimentos íntimos. Mas, para Greene (2018) e Haidt (2018) enquanto os julgamentos utilitaristas são mais frios e calculistas, os sentimentos, frequentemente, conduzem as pessoas a fazerem julgamentos deontológicos. O primeiro princípio dessa psicologia moral é Intuições vem antes, raciocínio estratégico depois. Dentre os entrevistados que optaram pela resposta deontológica, ou seja, que não matariam Ellie para salvar a humanidade, o fato de ter jogado o game justificou sua escolha. Dentre aqueles que jogaram Last of Us, salvar Ellie (40\%) foi unânime. Essa decisão, ao ignorar a fabricação de uma provável vacina destinada à cura da humanidade, foge de qualquer tipo de utilitarismo, indicando uma postura deontológica, mas que confirma o fato de que a racionalidade é influenciada por sentimentos. Tanto o dilema Last of Us quanto o The Walking Dead apresentaram diferenças significativas com relação as respostas de acordo com o sexo do jogador (Tabela 4).

Tabela 4. Resultados dos dilemas por sexo

\begin{tabular}{lcc}
\hline Dilemas & Masc. (\%) & Fem. (\%) \\
\hline Dilema II - The Walking Dead & 23,0 & 7,0 \\
Matá-la & 27,0 & 33,0 \\
Dar a arma para ela se matar & 0 & 10,0 \\
Outras soluções & & \\
\hline Dilema III - The Last of Us & 61,6 & 33,6 \\
Salvar a humanidade & 30,6 & 48,6 \\
Salvar Ellie & 23,4 & 32,9 \\
Ellie decide & 68,8 & 16,5 \\
Joel decide & 2,1 & 44,6 \\
Outras soluções & & \\
\hline
\end{tabular}

Dentre os entrevistados que preferiram "Salvar a humanidade" ao invés de Salvar Ellie, 61,6 \% eram do sexo masculino e 33,6 \% do sexo feminino. Já a opção de "Salvar Ellie" foi escolhida por 48,6\% das mulheres, e apenas 30,6 $\%$ dos homens. A respeito de "Ellie decidir sobre seu destino", apenas $23,4 \%$ dos homens concordaram. Já entre as mulheres, $32,9 \%$ relataram que a decisão cabia somente a ela. Com relação a "Joel decidir sobre a vida de Ellie", $68,8 \%$ dos homens concordaram e apenas $16,5 \%$ das mulheres concordaram que a decisão sobre a vida de Ellie caberia a Joel. Somente $2,1 \%$ dos participantes do sexo masculino elaboraram "outras soluções" para o dilema, contrastando significativamente com $44,6 \%$ das participantes que deram outras sugestões.

Tanto o dilema Last of Us quanto o The Walking Dead apresentaram diferenças significativas com relação ao gênero dos entrevistados. Gilligan (1982) reivindica a existência de duas formas válidas, mas distintas de ética sobre a tomada de decisões morais, correspondentes a dois tipos diferentes de identidade - masculina e feminina - ressaltando a singularidade feminina, não deixando-a subordinada à masculina, como foi propagado pelos estudos tradicionais. 
Enquanto a abordagem masculina, nas sociedades ocidentais, tem como princípios o respeito pelo outro, sendo orientada pela justiça, a abordagem feminina a moralidade está relacionada à responsabilidade das pessoas umas para com as outras, destacando o cuidar como orientação. A decisão moral é tomada de acordo com o impacto ocasionado na relação com os outros.

Para Gilligan, as análises indicam que as mulheres privilegiam as relações e o fato de estarem no centro de uma rede relacional, assim como temem o isolamento e enfatizam as formas de integração. Ao contrário, os homens possuem um modo individualista, em que a primazia pelo "Eu”, propicia a distinção entre si e os outros, afirmando-se pela separação, o que poderia explicar um círculo de conhecidos, mas poucos amigos íntimos.

Os jogadores entrevistados se relacionam com os conteúdos morais de modo "utilitarista", pois levam em consideração o fato de estarem em um mundo virtual. O estudo sobre os jogos eletrônicos e a ética nos espaços virtuais, desenvolvido por Ramos (2016), corrobora com a presente pesquisa. Utilizando como método a cartografia a autora identificou que o jogador leva em consideração os aspectos éticos de forma distinta e propõe o conceito de ciberética, como a ética dos jogos eletrônicos. Essa ética faz com que o jogador possa avaliar as regras deliberadas visando orientar e apoiar o seu comportamento no mundo virtual. Em estudo anterior, Ramos (2012) investigou a influência que as experiências em mundos virtuais advindas da interação com os jogos eletrônicos têm sobre a competência do juízo moral dos jogadores. Utilizando o teste de juízo moral (MJT) em 102 universitários submetidos a sessões com os mais variados tipos de jogos, as análises não constataram diferenças significativas entre alunos jogadores e não jogadores com relação ao juízo moral. Dessa forma, a autora questiona e relativiza a influência dos jogos no juízo moral dos sujeitos. Francis et al. (2017) apresenta dados que também condizem com os resultados deste estudo. Os pesquisadores utilizaram o dilema do trem de Greene em um contexto de Realidade Virtual (RV), analisando a ação moral e o julgamento moral de cada participante. Complementar a essa tática, os autores utilizaram equipamentos de monitoramento da frequência cardíaca dos 40 entrevistados. Os resultados indicaram um número muito maior de respostas utilitárias - matando uma vida para salvar muitas outras - com a frequência cardíaca aumentando significativamente durante a resolução dos dilemas. Os autores da pesquisa sugerem que a ação moral pode ser vista como um construto independente para o julgamento moral, com os métodos de RV oferecendo novas perspectivas para investigar e avaliar o comportamento moral. Já as respostas "deontológicas", embora em um primeiro momento demonstre ser derivadas de princípios morais superiores e justificados por um criterioso raciocínio, são na verdade provenientes de intuições. Tal afirmação é explicada pela psicologia moral intuicionista: raciocínios morais são utilizados visando aos melhores motivos para que alguém concorde com determinado juízo ou julgamento, e não para construir reais motivos de como chegar a determinado juízo ou opinião. Intuições vêm antes, raciocínio estratégico depois. As emoções ditam os raciocínios. A formação moral se dá por meio da intuição, uma mescla de ambiente, cultura e experiências adquiridas. A maioria dos valores morais não se constitui por meio de análise racional e lógica, mas das intuições.

\section{Considerações finais}

O objetivo deste estudo foi analisar como os jogadores se relacionam moralmente com os conteúdos morais presentes nos jogos eletrônicos, assim destaca-se que os jogadores tendem a transferir várias de suas convicções, insatisfações, preconceitos e valores do mundo real aos jogos. Em um mundo de possibilidades, as resoluções dos conflitos morais apresentadas nos jogos, refletem elementos norteadores moralmente reais do jogador. Contudo, tais elementos se dissolvem, e utilizando a máxima pós-moderna, se tornam fragmentados, líquidos, se modificam no ciberespaço, pois são poucas as sanções ou punições para os comportamentos virtuais ditos "imorais". Os jogos são paraísos virtuais e a possibilidade de satisfação dos desejos como em uma catarse é algo irresistível e inevitável ao jogador. Ao levantar a questão da moralidade contemporânea relacionada aos jogos eletrônicos, a preocupação foi como realizar o diálogo entre dois domínios que, aparentemente, eram tão distantes, teoricamente e empiricamente. A surpresa foi que no desenrolar desta pesquisa, tais áreas se mostraram muito mais próximas do que imaginado. $\mathrm{O}$ uso dos dilemas foi fundamental nesse aspecto, e ao aproximá-los ao contexto do jogador, se apresentaram como instrumentos fundamentais na construção deste estudo. Os jogos se tornaram ótimas ferramentas para discussões sobre dilemas 
éticos e podem se tornar um bom catalisador para discutir os temas atuais. Não só os jogos, mas outras mídias contemporâneas como, por exemplos, as redes sociais e aplicativos de relacionamentos podem e devem se tornar uma ferramenta valiosa e assaz importante para debates sobre as tecnologias recentes. Devemos ressaltar que o estudo apresenta limitações relacionadas, em primeiro lugar, com uma amostra de participantes relativamente pequena face ao elevado número jogadores; e, em segundo lugar, os instrumentos metodológicos usados, apesar de permitirem obter dados importantes, ainda são, principalmente no caso dos videodilemas, uma técnica recente sendo necessário o desenvolvimento de futuras investigações com amostras maiores de participantes.

\section{Agradecimentos}

À Fundação de Amparo à Pesquisa do Estado de São Paulo (FAPESP)

\section{Contribuições dos autores}

Evangelista, V. M. A. participou da concepção, delineamento, coleta de dados da pesquisa, análise estatística dos dados da pesquisa, interpretação dos resultados e redação do artigo científico. Kadooka, A. participou da coleta de dados da pesquisa, análise estatística dos dados da pesquisa, e interpretação dos resultados. Lepre, R. M. participou da concepção, delineamento e interpretação dos resultados.

\section{Conflitos de interesses}

Nenhum conflito financeiro, legal ou político envolvendo terceiros (governo, empresas e fundações privadas, etc.) foi declarado para nenhum aspecto do trabalho submetido (incluindo, mas não se limitando a subvenções e financiamentos, participação em conselho consultivo, desenho de estudo, preparação de manuscrito, análise estatística, etc.).

\section{Referências}

Biaggio, Â. (2006). Lawrence Kohlberg: ética e educação moral. Moderna.

Bloom, P. (2014). O que nos faz bons ou maus. Best Seller.

Castells, M. (2013). A Galáxia da Internet. Zahar.
Ellemers, N., Plagliaro, S., \& Barreto, M. (2013). Morality and behavioural regulation in groups: A social identity approach [Moralidade e regulamentação de comportamento em grupos: Uma abordagem de identidade social]. European Review of Social Psychology, 1, 160-193. https://doi.org/10.1080/10463283.2013.841490

Fiske, S. T. (2018). Stereotype Content: Warmth and Competence Endure [Estereótipo Conteúdo: Aquecimento e Resistência à Competência]. Current Directions in Psychological Science, 27(2), 67-73. https://doi.org/10.1177/0963721417738825

Francis, K. B., Howard, C., Howard, I. S., Gummerum, M., Ganis, G., Anderson, G., \& Terbeck, S. (2017). Virtual Morality: Transitioning from Moral Judgment to Moral Action? [Moralidade virtual: Transição do Julgamento Moral para a Ação Moral?]. Plos One, 12(1), 1-12. https://doi. org/10.1371/journal.pone.0170133

Giddens, A. (1991). As Consequências da Modernidade. UNESP.

Gilligan, C. (1982). In a different voice: Psycological Theory and Women's Development [Em uma voz diferente: Teoria Psicológica e Desenvolvimento da Mulher]. Harvard University Press.

Greene, J. (2018). As tribos morais a tragédia da moralidade do senso comum. Record.

Haidt, J. (2018). A mente moralista: Por que as pessoas boas são segregadas por política e religião. Alta Cult.

Iachini, T., Pagliaro, S., \& Ruggiero, G. (2015). Near or far? It depends on my impression: Moral information and spatial behavior in virtual interactions [Perto ou longe? Depende da minha percepção: Informações morais e comportamento espacial em interações virtuais]. Acto Psychologica, 161, 131-136. https://doi.org/10.1016/j. actpsy.2015.09.003

Kerr, A. (2003). Girls/Women Just Want to Have Fun - A Study of Adult Female Players of Digital Games [Meninas/ Mulheres Só Querem se Divertir - Um Estudo de Jogadoras Adultas de Jogos Digitais]. Digital Games Research, 270285. University of Utrecht, Utrecht. https://core.ac.uk/ download/pdf/297010270.pdf

Khaled Jr, S. H. (2018). Videogame e violência: Cruzadas morais contra os jogos eletrônicos no Brasil e no mundo. Civilização Brasileira.

Lipovetsky, G. (2009). O Império do Efêmero. Companhia das Letras.

Lipovetsky, G. (2016). De la ligereza. Anagrama.

Mcgonigal, J. (2012). Realidade em jogo: por que os games nos tornam melhores e como eles podem mudar o mundo. Best Seller. 
Medeiros, M. D. (2013). Jogos eletrônicos, mundos virtuais e identidade: o si mesmo como experiência alteritária [Tese de Doutorado, Universidade Federal do Ceará]. Repositório Institucional UFC. http://www.repositorio.ufc.br/handle/ riufc/6044

Mendes, C. L. (2006). Jogos eletrônicos: diversão, poder e subjetivação. Papirus.

Przybylski, A. K., \& Mishkin, A. F. (2015). How the quantity and quality of electronic gaming relates to adolescents academic engagement and psychosocial adjustment [Como a quantidade e a qualidade dos jogos eletrônicos se relacionam com o envolvimento acadêmico dos adolescentes e o ajuste psicossocial]. Psychology of Popular Media Culture, 5(2), 145-156. https://psycnet.apa.org/ doi/10.1037/ppm0000070

Przybylski, A. K., Weinstein, N., \& Murayama, K. (2017). Internet Gaming Disorder: Investigating the Clinical Relevance of a New Phenomenon [Desordem nos jogos pela Internet:
Investigando a Relevância Clínica de um Novo Fenômeno]. Am J Psychiatry, 174(3), 230-236. https://psycnet.apa.org/ doi/10.1037/ppm0000070

Ramos, D. K. (2012). Jogos eletrônicos e juízo moral: um estudo com adolescentes do ensino médio. Psicologia: teoria e prática, 14(1), 97-112. http://pepsic.bvsalud. org/scielo.php?script=sci_arttext\&pid=S1516$36872012000100008 \& \operatorname{lng}=p t \& t \operatorname{lng}=p t$

Ramos, D. K. (2016). Ciberética: vias do desejo nos jogos eletrônicos. Novas Edições Acadêmicas.

Salen, K., \& Zimmerman, E. (2012). Regras do jogo: fundamentos do design de jogos. Blucher.

Turkle, S. (2017). Alone Together: Why We Expect More from Technology and Less from Each Other [Sozinhos juntos: Por que esperamos mais da tecnologia e menos um do outro]. Basic Books. 